\title{
Gorbatschow, M. (2019). Was jetzt auf dem Spiel steht. Mein Aufruf für Frieden und Freiheit.
}

\author{
München: Siedler Verlag. 186 S., ISBN: 978-3-8275-0128-8, € 18,-.
}

\section{Gerhard Simon}

Online publiziert: 27. April 2020

(C) Der/die Autor(en) 2020

Michail Gorbatschow hat als aktiver Politiker vor 30 Jahren Weltpolitik gemacht: Das Ende des Kalten Krieges ist ohne ihn nicht denkbar. Dabei waren sowohl seine Analyse der Lage als auch seine Zukunftsvision falsch, wie er selbst mehr oder weniger offen einräumt: Seine Analyse unterstellte, dass das sowjetische Regime reformierbar sei, und seine Zukunftsvision war eine demokratische Ordnung von Vancouver bis Wladiwostok.

In diesem schmalen Band unternimmt Gorbatschow erneut eine Analyse der Gegenwart und entwirft eine Zukunftsvision. Einerseits werden die neuen Entwicklungen in der Welt zumindest beim Namen genannt: So erfährt der Leser etwas über die „Islamische Welt“ (S. 123-126) oder die „Ökologische Herausforderung“ (S. 5865). Andererseits wirkt die Analyse wie vor Jahrzehnten stehen geblieben. Zentrales Element der Weltpolitik ist für Gorbatschow nach wie vor der Konflikt zwischen den beiden Supermächten USA und Russland, wobei Amerika eine aggressive Dominanzpolitik mit dem Ziel der Errichtung einer unipolaren Weltordnung unterstellt wird. Weder findet die neue Supermacht China, die Russland inzwischen in vieler Hinsicht in den Schatten stellt, angemessene Berücksichtigung, noch geht Gorbatschow auf die Probleme ein, die eben daraus resultieren, dass die USA sich aus der Weltmachtrolle zurückziehen.

Russland, „das einzige Land, in dem ich mir vorstellen kann, zu leben“ (S. 140), sieht Gorbatschow von allen Seiten bedrängt und ungerechtfertigten Sanktionen des Westens ausgesetzt. Soweit politische Überlegungen konkret werden, ist Gorbatschow voll auf Putin-Kurs. Zwar äußert er milde Kritik am Autoritarismus des

Prof. Dr. G. Simon ( $₫)$

Historisches Institut, Universität zu Köln, Albertus-Magnus-Platz, 50923 Köln, Deutschland E-Mail: g.simon@uni-koeln.de 
russischen Präsidenten, aber vor allem außenpolitisch solidarisiert er sich uneingeschränkt mit ihm.

Für Gorbatschow ist die Krim Russland und die Ukraine kein Land, das einen eigenen Weg in die Zukunft beanspruchen dürfe. Immer wieder schreibt sich Gorbatschow - und zu Recht - das Verdienst zu, die Länder Ostmitteleuropas in die Freiheit des eigenen Weges entlassen zu haben, doch der Ukraine wird implizit die Qualität eines selbständigen Staates und eigenen Weges verweigert. Sie hat nicht das Recht, sich aus der Hegemonie Russlands zu lösen, denn das berühre „die Interessen Russlands unmittelbar“ (S. 108).

Die Zukunftsvision Gorbatschows ist rigoros und umfassend: Abschaffung aller atomaren Waffen und Gewaltmonopol der Vereinten Nationen. Vor allem aber müsse das Ziel darin bestehen, ,Politik und Moral zu vereinen“ (S. 86). „Moral, universelle Werte, Achtung vor [...] der Würde des Menschen - all das muss zu einem integralen Bestandteil der Weltpolitik werden“ (S. 91). Diese Vision wird mit dem heute gängigen Alarmismus vorgetragen: „Wir sind zwei Minuten vom Krieg entfernt“ (S. 7).

Es ist schwer zu erkennen, wie diese Überlegungen des politischen Denkers Gorbatschow einen Beitrag leisten könnten zu einem praxisbezogenen Diskurs über die ungelösten Probleme in der Welt. Die Spreizung zwischen der unkritischen Unterstützung für den außenpolitischen Kurs Putins einerseits und andererseits der Vision einer idealen Welt ohne Waffen und geleitet von einer Politik der Menschenwürde erscheint unüberbrückbar. Aber dem Leser soll offenbar suggeriert werden, dass eine Unterstützung für die Politik des Kremls ihn zugleich zum Anhänger einer totalen atomaren Abrüstung und der Moral der Würde in der Politik macht. Nicht jeder und jedem wird das einleuchten. Zu schwer wiegen Fakten und Argumente, die in eine ganz andere Richtung weisen: Der Kreml verletzt mit seiner Politik der einseitigen und aggressiven Grenzverschiebungen im postimperialen Raum die Würde des Menschen. Nicht atomare Abrüstung bestimmt die Agenda, sondern neue Waffen sollen die Militärmacht Russland ,unbesiegbar"1 machen.

Funding Open Access funding provided by Projekt DEAL.

Open Access Dieser Artikel wird unter der Creative Commons Namensnennung 4.0 International Lizenz veröffentlicht, welche die Nutzung, Vervielfältigung, Bearbeitung, Verbreitung und Wiedergabe in jeglichem Medium und Format erlaubt, sofern Sie den/die ursprünglichen Autor(en) und die Quelle ordnungsgemäß nennen, einen Link zur Creative Commons Lizenz beifügen und angeben, ob Änderungen vorgenommen wurden.

Die in diesem Artikel enthaltenen Bilder und sonstiges Drittmaterial unterliegen ebenfalls der genannten Creative Commons Lizenz, sofern sich aus der Abbildungslegende nichts anderes ergibt. Sofern das betreffende Material nicht unter der genannten Creative Commons Lizenz steht und die betreffende Handlung nicht nach gesetzlichen Vorschriften erlaubt ist, ist für die oben aufgeführten Weiterverwendungen des Materials die Einwilligung des jeweiligen Rechteinhabers einzuholen.

Weitere Details zur Lizenz entnehmen Sie bitte der Lizenzinformation auf http://creativecommons.org/ licenses/by/4.0/deed.de.

\footnotetext{
1 Putin, zit. n. t-online.de. (2019, 28. Dez.). Russland nimmt Hyperschall-Rakete in Betrieb. https://www. t-online.de/nachrichten/ausland/id_87058272/russland-nimmt-rakete-avangard-in-betrieb-putin-haeltsie-fuer-unbesiegbar-.html. Zugegriffen: 04. April 2020.
} 